\title{
Relieving the current crowding effect in flip-chip solder joints during current stressing
}

\author{
S.W. Liang, T.L. Shao, and Chih Chen ${ }^{\text {a) }}$ \\ National Chiao Tung University, Department of Material Science and Engineering, \\ Hsin-chu 30050, Taiwan, Republic of China \\ Everett C.C. Yeh \\ FrontAnD Technology, Hsinchu 30050, Taiwan, Republic of China \\ K.N. Tu \\ Department of Materials Science and Engineering, University of California-Los Angeles, \\ Los Angeles, California 90095
}

(Received 31 January 2005; accepted 19 September 2005)

\begin{abstract}
Three-dimensional simulations for relieving the current crowding effect in solder joints under current stressing were carried out using the finite element method. Three possible approaches were examined in this study, including varying the size of the passivation opening, increasing the thickness of $\mathrm{Cu}$ underbump metallization (UBM), and adopting or inserting a thin highly resistive UBM layer. It was found that the current crowding effect in the solder bump could be successfully relieved with the thick $\mathrm{Cu}$ UBM or with the highly resistive UBM. Compared to the solder joint with $\mathrm{Al} / \mathrm{Ni}(\mathrm{V}) / \mathrm{Cu} \mathrm{UBM}$, for instance, the maximum current density in a solder bump decreased dramatically by a factor of fifteen, say from $1.11 \times 10^{5} \mathrm{~A} / \mathrm{cm}^{2}$ to $7.54 \times$ $10^{3} \mathrm{~A} / \mathrm{cm}^{2}$ when a $20-\mu \mathrm{m}$-thick Cu UBM was used. It could be lowered by a factor of seven, say to $1.55 \times 10^{4} \mathrm{~A} / \mathrm{cm}^{2}$, when a $0.7-\mu \mathrm{m}$ UBM of $14770 \mu \Omega \mathrm{cm}$ was adopted. It is worth noting that although a resistive UBM layer was used, the penalty on overall resistance increase was negligible because the total resistance was dominated by the $\mathrm{Al}$ trace instead of the solder bump. Thermal simulation showed that the average temperature increase due to Joule heating effect was only $2.8^{\circ} \mathrm{C}$ when the solder joints with UBM of $14770 \mu \Omega \mathrm{cm}$ were applied by $0.2 \mathrm{~A}$.
\end{abstract}

\section{INTRODUCTION}

The flip-chip solder joint has become the most important technology of high-density packaging in the microelectronics industry. ${ }^{1}$ Thousands of solder bumps can be fabricated into one chip. To meet performance requirements, the input/output (I/O) numbers keep increasing, and the size of the joints progressively shrinks. Their diameter is about $100 \mu \mathrm{m}$ or less. ${ }^{2}$ The design rule of packaging requires that each bump is to carry $0.2-0.4 \mathrm{~A}$, resulting in a current density of approximately $2 \times 10^{3}$ to $2 \times 10^{4} \mathrm{~A} / \mathrm{cm}^{2}$. Therefore, electromigration has become an important reliability issue for flip-chip solder joints. $^{3-5}$

In this work, current density distribution in a solder joint was thoroughly studied by a three-dimensional finite element simulation. It was found that the maximum

\footnotetext{
a) Address all correspondence to this author.

e-mail: chih@cc.nctu.edu.tw

DOI: 10.1557/JMR.2006.0004
}

current density in a solder bump can be much higher than the average one that was previously projected. It locates itself near the solder/underbump metallization (UBM) interface, which serves as a vacancy flux divergence plane and favors electromigration occurring at that location. Consequently, the solder joint is more prone to electromigration. The cause of such locally high current density is a result of the current crowding effect. Current crowding occurring in the solder joints is due to the current flow experiencing a dramatic geometrical and resistance transition from the thin on-chip metal line to the solder bump. Because the cross-section of the $\mathrm{Al}$ trace on the chip side is about two orders smaller than that of the solder joints, the majority of the current will tend to gather near the Al/UBM entrance point to enter the solder bump instead of spreading uniformly across the opening before entering the bump. The materials near the entrance point experience a current density of about one order of magnitude higher than the average value. The materials included a bump metallization (UBM), intermetallic compound (IMC), and solder, where the 
solder has high lattice diffusivity, higher resistivity, lower Young's modulus, and a higher effective charge number than the other two materials. ${ }^{3,6-9}$ Therefore, the current crowding effect enhances the possibility of voids forming in the solder near the entrance and then propagating to cause electromigration failure. Current crowding

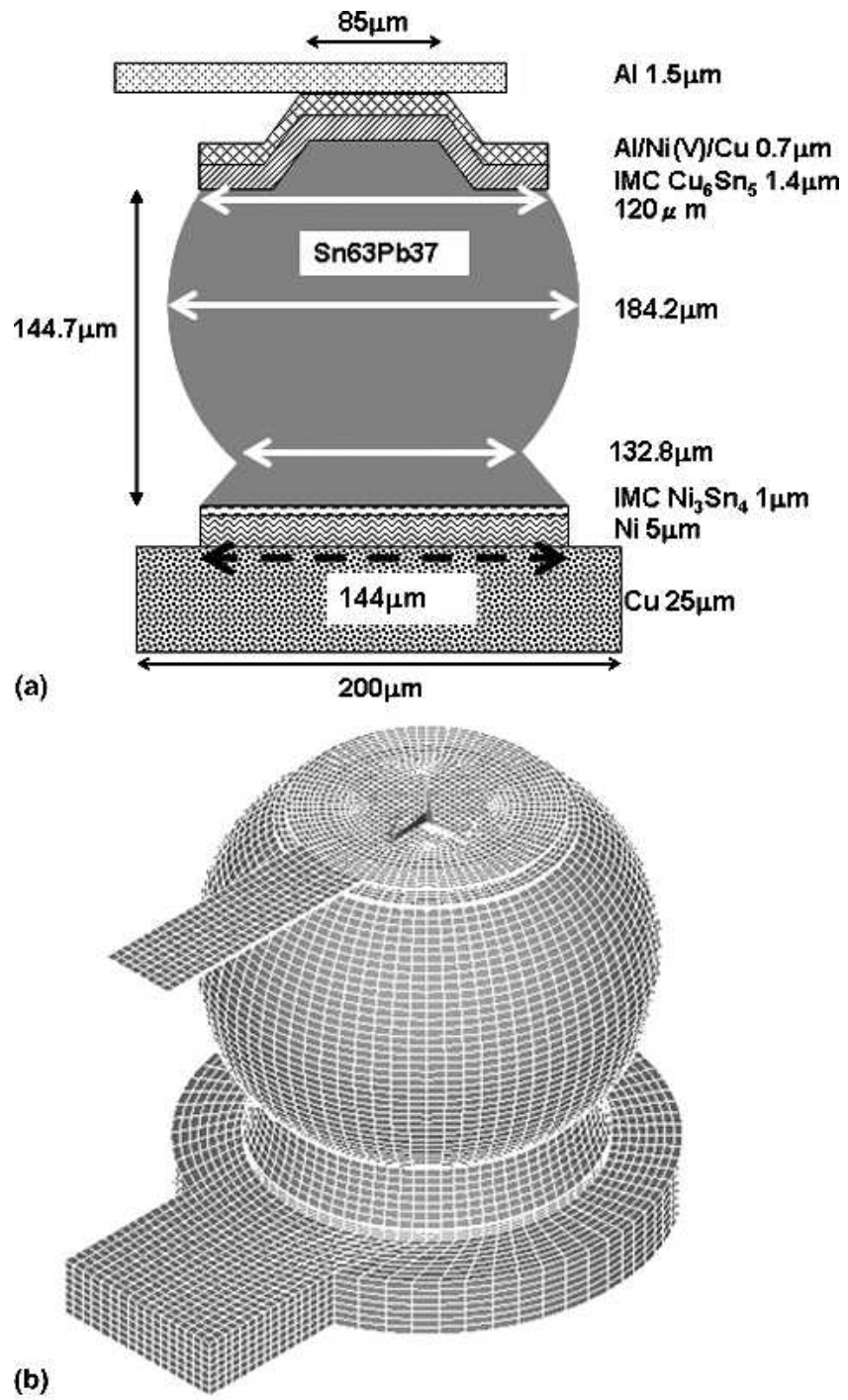

(b)

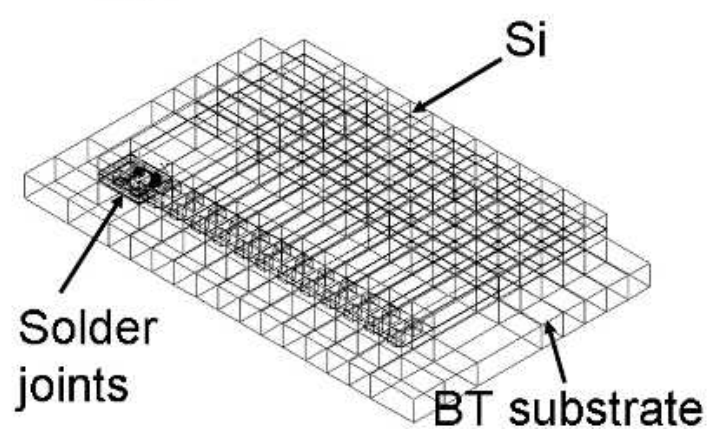

FIG. 1. (a) Schematic diagrams of the solder joint with $\mathrm{Al} \mathrm{Ni(V)/Cu}$ UBM used in this study. (b) Three-dimensional view of the model in (a) with meshes contained in it.
TABLE I. Properties of materials used in the simulation models.

\begin{tabular}{lcc}
\hline \hline \multicolumn{1}{c}{ Material } & $\begin{array}{c}\text { Thermal conductivity } \\
\left(\mathrm{W} / \mathrm{m}{ }^{\circ} \mathrm{C}\right)\end{array}$ & $\begin{array}{c}\text { Resistivity } \\
(\mu \Omega \mathrm{cm})\end{array}$ \\
\hline Silicon(chip) & 147.0 & $\ldots$ \\
$\mathrm{Al}$ trace & 238.0 & 3.2 \\
$\mathrm{UBM}(\mathrm{Ti}+\mathrm{Cr} / \mathrm{Cu}+\mathrm{Cu})$ & 147.6 & 18.8 \\
Eutectic $\mathrm{SnPb}$ & 34.1 & 14.6 \\
$\mathrm{Ni}$ & 70.0 & 6.8 \\
$\mathrm{Cu}$ pad & 403.0 & 1.7 \\
$\mathrm{BT}($ substrate $)$ & 0.7 & $\ldots$ \\
Underfill & 0.55 & $\ldots$ \\
Polyimide & 0.26 & $\ldots$ \\
Ni(V) & 71.4 & 63.2 \\
\hline \hline
\end{tabular}

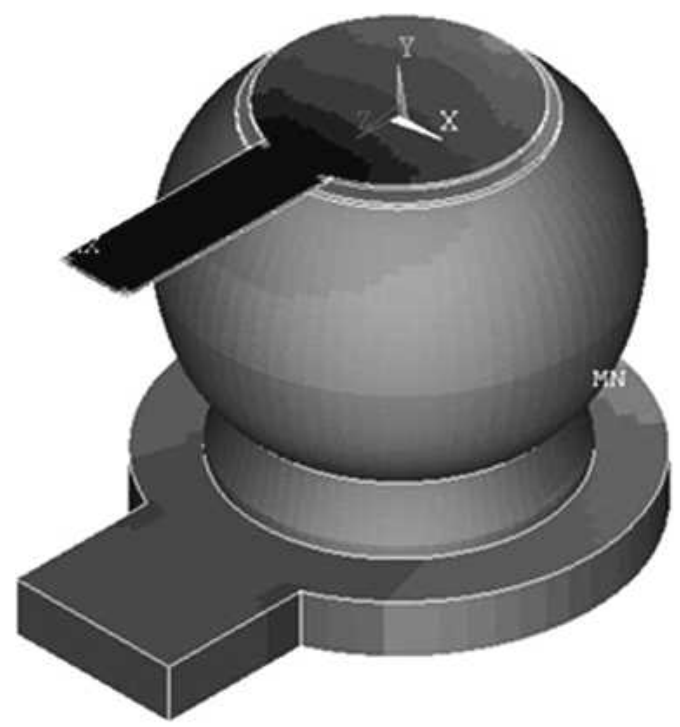

(a)

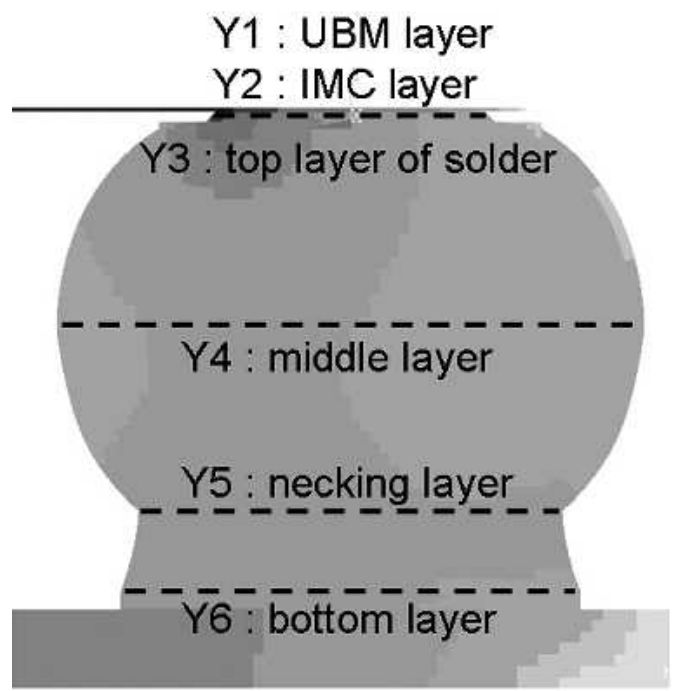

(b)

FIG. 2. Current density distribution in the solder joint with $\mathrm{Al} \mathrm{Ni(V)/}$ $\mathrm{Cu}$ UBM when powered by $0.567 \mathrm{~A}$. (b) Cross-sectional view along the Z-axis of (a). Current crowding occurs in the entrance of the Al trace. The dotted lines show the six cross-sections examined in this study. 

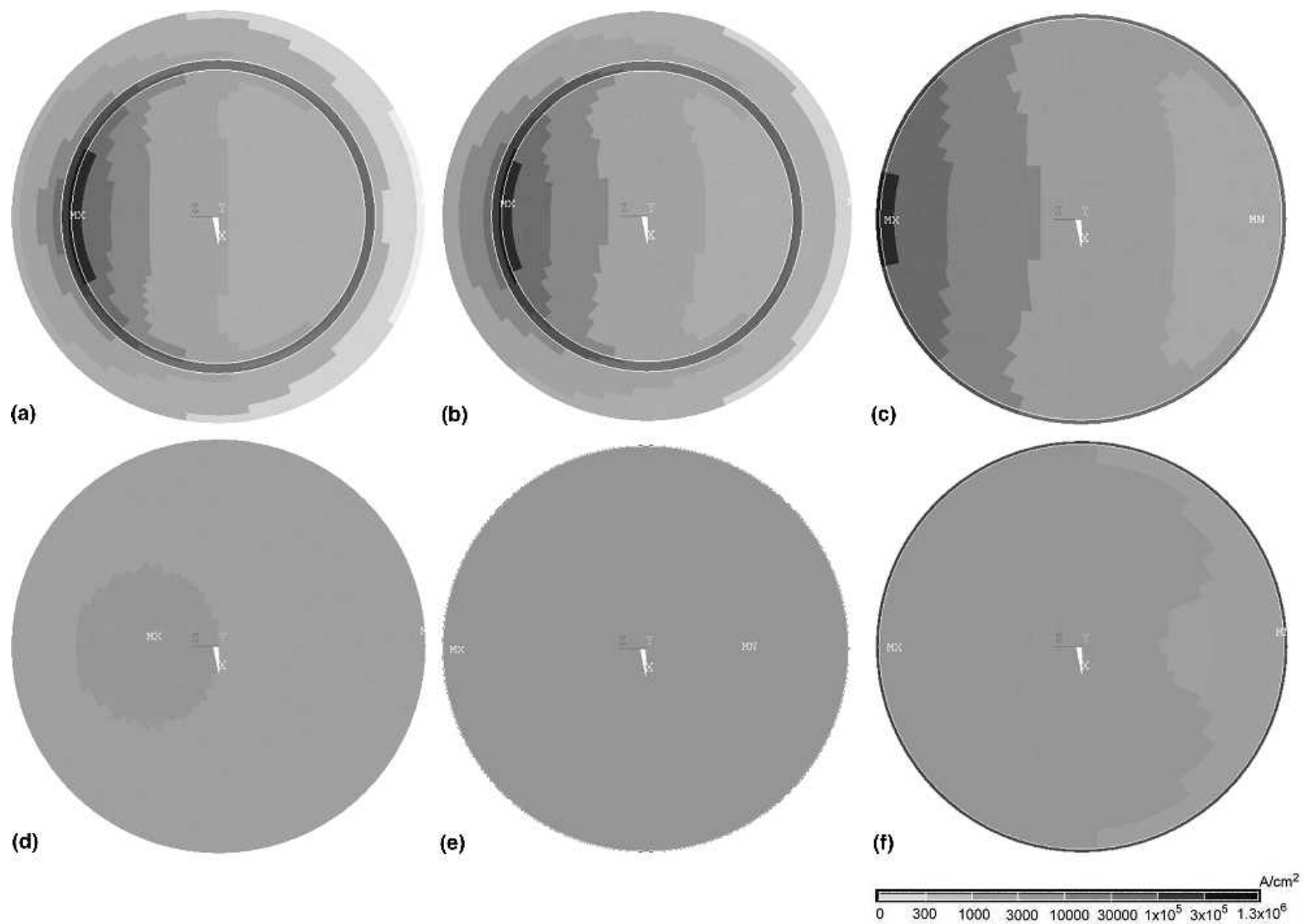

FIG. 3. Current density distribution in the different cross-sections: (a) cross-section Y1, located inside the UBM; (b) cross-section Y2, the IMC layer between the UBM and the solder; (c) cross-section Y3, the top layer of the solder connected to the IMC; (d) cross-section Y4, which has the largest diameter in the joint; (e) cross-section Y5, which has a smaller diameter due to the solder mask process; (f) cross-section Y6, which is situated at the bottom of the solder joint.

plays a critical role in the electromigration failure of the solder joints. ${ }^{10}$

Hence, increasing the electromigration resistance of the joints is an important and urgent issue. There are two approaches to increasing electromigration resistance: first, using a solder alloy that has better electromigration resistance; second, relieving the current crowding effect in solder joints by proper circuit or UBM design. For the former approach, $\mathrm{Wu}$ et al. developed a $\mathrm{Pb}$-free solder alloy that has excellent electromigration resistance, close to that of the high-Pb solder. ${ }^{11}$ For the latter approach, it is expected that relieving the current crowding effect in solder joints would retard the formation rate of the voids and thus would increase the lifetime of the solder joints. However, no literature related to this issue has been reported so far. For this paper, we used finite element analysis to simulate the current density distribution of the solder joints with various structures of flip-chip solder joints. Possible solutions for the relieving current crowding effect will be proposed.

TABLE II. Maximum current density and crowding ratios at different cross sections for the solder joint with the Al/Ni(V)/Cu thin film UBM.

\begin{tabular}{|c|c|c|c|c|c|c|c|}
\hline & & \multicolumn{6}{|c|}{ Cross section } \\
\hline \multicolumn{2}{|c|}{ Method } & $\begin{array}{l}\text { Y1, UBM } \\
\text { layer }\end{array}$ & $\begin{array}{l}\text { Y2, IMC } \\
\text { layer }\end{array}$ & $\begin{array}{c}\text { Y3, top layer } \\
\text { of solder }\end{array}$ & $\begin{array}{c}\text { Y4, middle } \\
\text { layer of solder }\end{array}$ & $\begin{array}{l}\text { Y5, necking } \\
\text { layer of solder }\end{array}$ & $\begin{array}{c}\text { Y6, bottom } \\
\text { layer of solder }\end{array}$ \\
\hline \multirow[t]{2}{*}{ Standard } & Maximum & $2.09 \times 10^{5}$ & $1.81 \times 10^{5}$ & $1.11 \times 10^{5}$ & $3.45 \times 10^{3}$ & $7.55 \times 10^{3}$ & $5.91 \times 10^{3}$ \\
\hline & Ratio & 41.9 & 36.2 & 22.2 & 0.7 & 1.5 & 1.2 \\
\hline
\end{tabular}




\section{SIMULATION}

The simulation model used in this study is schematically shown in Fig. 1(a). Throughout this text, it will be denoted as the standard model. A thin film UBM of $0.4-\mu \mathrm{m} \mathrm{Al} / 0.3-\mu \mathrm{m} \mathrm{Ni}(\mathrm{V}) / 0.4-\mu \mathrm{m} \mathrm{Cu}$ was adopted for the chip side, and Ni metallization was used on the substrate side. Eutectic $\mathrm{SnPb}$ solder was adopted for the bump

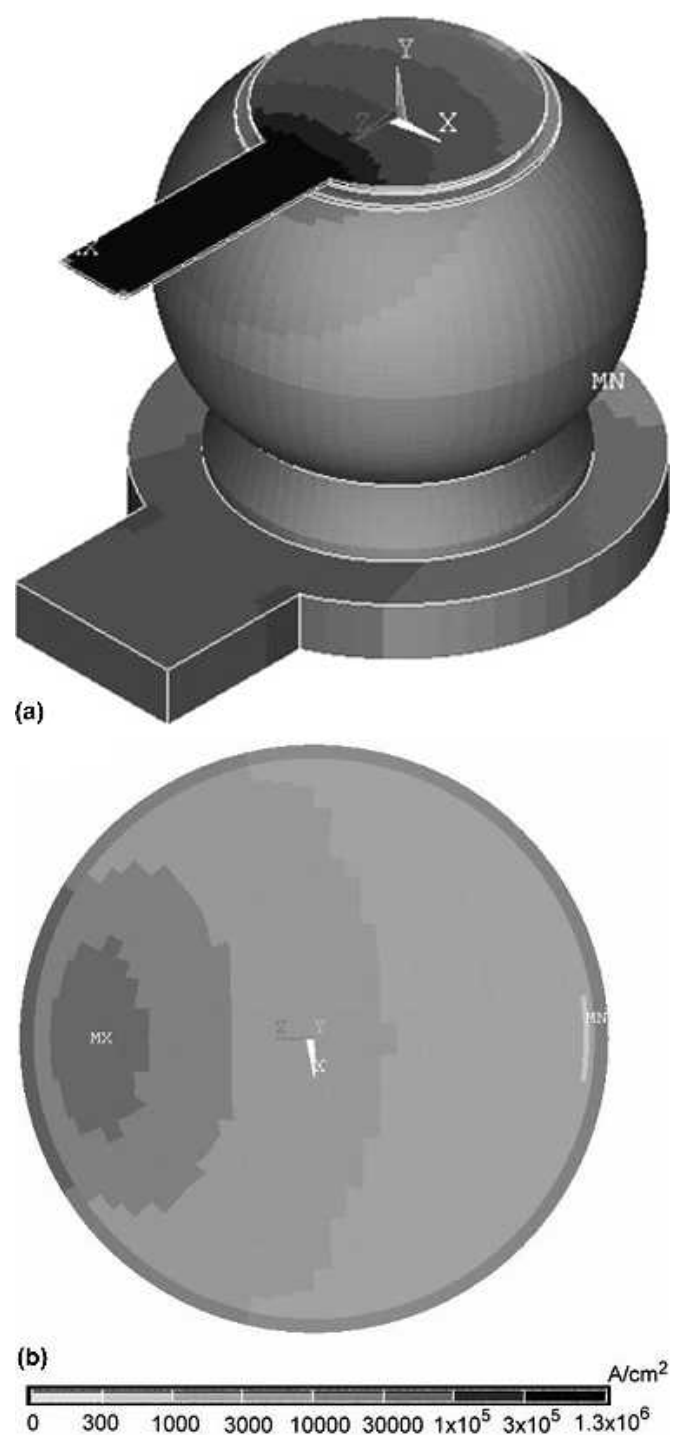

FIG. 4. (a) 3D current density distribution in the solder joint with a larger passivation opening of $100 \mu \mathrm{m}$ in diameter. (b) Current density distribution in the top layer of the solder (cross-section Y3) in (a). materials. The $\mathrm{Cu}$ layer in the UBM was assumed to be completely consumed to form $1.4 \mu \mathrm{m} \mathrm{Cu}_{6} \mathrm{Sn}_{5}$ IMC. Therefore, an effective layer of $0.7-\mu \mathrm{m}$ UBM with an effective resistivity of $29.54 \mu \Omega \mathrm{cm}$ was used in the simulation model. On the substrate side, we assumed that $1 \mu \mathrm{m} \mathrm{Ni}{ }_{3} \mathrm{Sn}_{4}$ IMC was formed in the interface of the solder and the Ni metallization. Both $\mathrm{Cu}_{6} \mathrm{Sn}_{5}$ and $\mathrm{Ni}_{3} \mathrm{Sn}_{4}$ IMCs were assumed to be the layered-type. The resistivity and thermal conductivity values of the materials used in this simulation are listed in Table I. The model used in this study was SOLID69 8-node hexahedral coupled field element using Ansys simulation software (Ansys Inc., PA). For thermal simulation, we used an infrared microscope to measure the temperature in the solder bumps during current stressing ${ }^{12}$ and then adjusted the simulation parameters so that the simulated temperature in the solder matched the one measured by the infrared microscope under the same applied current. The threedimensional (3D) schematic solder joint with meshes is shown in Fig. 1(b). The dimension of the mesh was $3.8 \mu \mathrm{m}$. The passivation and UBM openings are 85 and $120 \mu \mathrm{m}$ in diameter, respectively. The contact opening on the substrate is $144 \mu \mathrm{m}$ in diameter. The dimension of the $\mathrm{Al}$ trace is $34 \mu \mathrm{m}$ wide and $1.5 \mu \mathrm{m}$ thick, whereas the $\mathrm{Cu}$ line on the substrate side is $80 \mu \mathrm{m}$ wide and $25 \mu \mathrm{m}$ thick. A current of $0.567 \mathrm{~A}$ was applied from the $\mathrm{Al}$ trace, which drifted out of the bump from the $\mathrm{Cu}$ line. If one assumes the current drifts uniformly through the joint, the average current density in the $\mathrm{Al}$ trace was $1.11 \times 10^{6} \mathrm{~A} / \mathrm{cm}^{2}$, and the calculated average current densities were $5.01 \times 10^{3}$ and $3.48 \times 10^{3} \mathrm{~A} / \mathrm{cm}^{2}$ for the UBM opening of the chip side and the contact opening of the substrate side, respectively. Figure 1(c) shows the constructed model for thermal simulation, in which only two solder joints were stressed by current, as indicated by one of the arrows in the figure. The dimension of the $\mathrm{Si}$ chip was $7.0 \times 4.8 \mathrm{~mm}$ and the thickness was $290 \mu \mathrm{m}$, whereas the dimension of the bismaleimide triazine (BT) substrate was $5.4 \mathrm{~mm}$ wide, $9.0 \mathrm{~mm}$ long, and $380 \mu \mathrm{m}$ thick.

The current density distribution of the flip-chip solder joint was shown in Fig. 2(a). Current crowding is clearly observed in the vicinity of the entrance of the Al trace into the solder bump. However, it spreads out prior to reaching the half distance of the bump height, and there is no obvious current crowding at the bottom of the

TABLE III. Maximum current density and crowding ratios at different cross sections for the solder joint with larger passivation opening.

\begin{tabular}{|c|c|c|c|c|c|c|c|}
\hline & & \multicolumn{6}{|c|}{ Cross section } \\
\hline \multicolumn{2}{|l|}{ Method } & $\begin{array}{l}\text { Y1, UBM } \\
\text { layer }\end{array}$ & $\begin{array}{l}\text { Y2, IMC } \\
\text { layer }\end{array}$ & $\begin{array}{l}\text { Y3, top layer } \\
\text { of solder }\end{array}$ & $\begin{array}{c}\text { Y4, middle } \\
\text { layer of solder }\end{array}$ & $\begin{array}{l}\text { Y5, necking } \\
\text { layer of solder }\end{array}$ & $\begin{array}{l}\text { Y6, bottom } \\
\text { layer of solder }\end{array}$ \\
\hline Passivation opening: & Maximum & $2.33 \times 10^{5}$ & $2.03 \times 10^{5}$ & $1.22 \times 10^{5}$ & $3.67 \times 10^{3}$ & $8.16 \times 10^{3}$ & $6.04 \times 10^{3}$ \\
\hline $100 \mu \mathrm{m}$ & Ratio & 46.6 & 40.6 & 24.4 & 0.7 & 1.6 & 1.2 \\
\hline
\end{tabular}




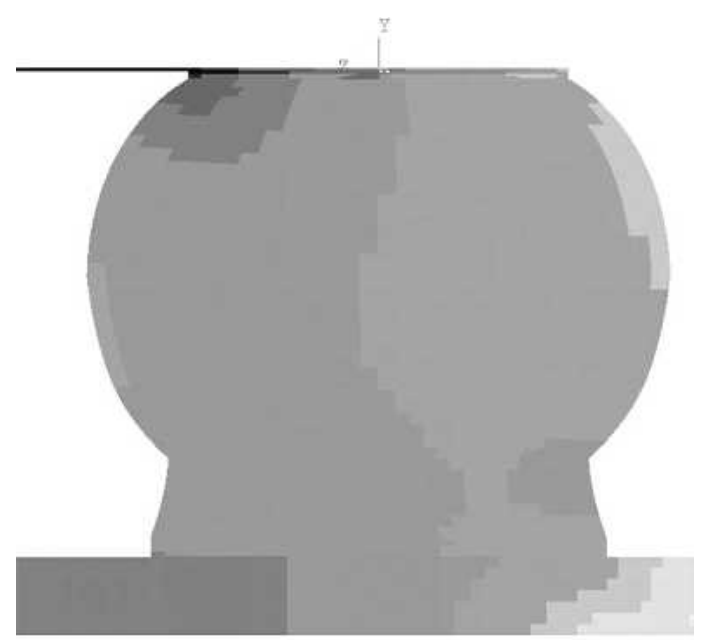

(a)

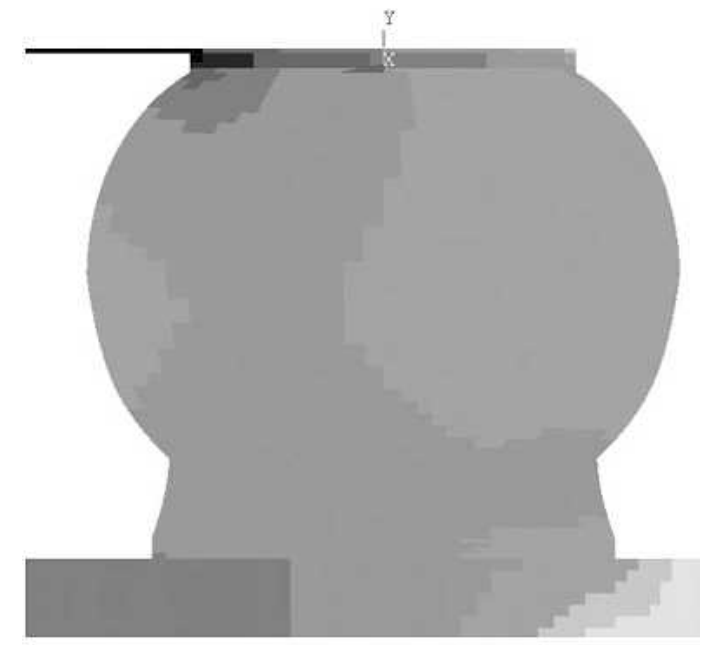

(b)

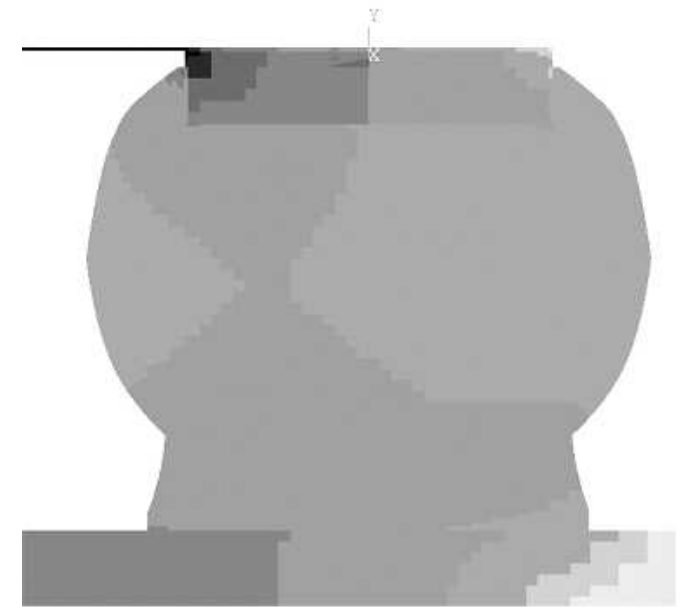

(c)

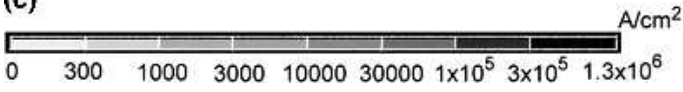

FIG. 5. Current density distribution in the cross-section along the $\mathrm{Z}$ axis for (a) $0.7-\mu \mathrm{m} \mathrm{Cu} \mathrm{UBM,} \mathrm{(b)} 5-\mu \mathrm{m} \mathrm{Cu} \mathrm{UBM}$, and (c) $20-\mu \mathrm{m} \mathrm{Cu}$ UBM. solder bump. The cross-sectional view of Fig. 2(a) along the Z-axis is shown in Fig. 2(b). The current crowding effect can be clearly seen at the entrance of the Al trace. The maximum current density inside the solder is $1.11 \times$ $10^{5} \mathrm{~A} / \mathrm{cm}^{2}$. In this paper, to evaluate the current crowding effect, we denote a "crowding ratio" as the local maximum current density divided by the average current density at the UBM opening. The average current density at the UBM opening is $5.01 \times 10^{3} \mathrm{~A} / \mathrm{cm}^{2}$ for the standard simulation model. Therefore, the corresponding crowding ratio for the solder near the entrance is 22.2, which means that the local current density at the solder bump near the $\mathrm{Al}$ entrance is 22.2 times larger than the average value at the UBM opening. The larger the value is, the higher the current crowding effect.

To examine the current density distribution in various locations of the joint, six cross-sections were inspected. Their locations are shown in Fig. 2(b), in which crosssection Y1 is located inside the UBM layer, cross-section Y2 represents the IMC layer, cross-section Y3 is located in the top layer of the solder joint connecting to the IMC, and cross-section $\mathrm{Y} 4$ is situated near the middle of the solder joint, which has the largest cross-section $184 \mu \mathrm{m}$ in diameter. Cross-section Y5 is situated between the middle and the bottom of the solder, which has a necking due to the necessity of there being a solder mask, and cross-section Y6 represents the bottom of the solder joint close to the $\mathrm{Ni}_{3} \mathrm{Sn}_{4}$ IMC on the substrate side.

The current density distributions at the six cross sections are shown in Figs. 3(a)-3(f). The current density distribution in the UBM layer is shown in Fig. 3(a), in which the maximum current density occurs near the $\mathrm{Al}$ entrance inside the passivation opening. The value reaches $2.09 \times 10^{5} \mathrm{~A} / \mathrm{cm}^{2}$, and its crowding ratio is as high as 41.9. For the IMC layer shown in Fig. 3(b), the maximum value is $1.81 \times 10^{5} \mathrm{~A} / \mathrm{cm}^{2}$, and the corresponding crowding ratio is 36.2 . The maximum current density inside the solder occurs near the $\mathrm{Al}$ entrance inside the passivation opening, as shown in Fig. 3(c). The value reaches $1.11 \times 10^{5} \mathrm{~A} / \mathrm{cm}^{2}$, and its crowding ratio remains as high as 22.2. For the remaining three layers, as shown in Figs. 3(d)-3(f), current distribution became more uniform, and thus the crowding ratios for the three layers were $0.7,1.5$, and 1.2 , respectively. Therefore, changing the angle between the $\mathrm{Al}$ trace and the $\mathrm{Cu}$ conductor may not be able to alter the current density distribution. These results agreed with the thermal simulation results conducted by Lee et al. ${ }^{13}$ The maximum current density and the crowding ratios at different cross sections for the solder joint are listed in Table II. Since the top-layer of the solder (Y3 plane) is the most vulnerable location during current stressing, we will examine the current density distribution on this layer for the following models that aim to relieve the current crowding effect. 


\section{METHODS FOR RELIEVING CURRENT CROWDING EFFECT}

\section{A. Effect of the dimension of the passivation opening}

Figure 4(a) shows the 3D distribution of current density in the solder bump with a larger passivation opening $100 \mu \mathrm{m}$ in diameter. The cross-section area of the contact opening in this case is 1.4 times larger than that of standard model. However, as seen in Fig. 4(a), current crowding still occurs in the vicinity of the $\mathrm{Al}$ entrance. Figure 4(b) shows the distribution of current density in the top layer of the solder. Surprisingly, its maximum current density increases up to $1.22 \times 10^{5} \mathrm{~A} / \mathrm{cm}^{2}$, which is higher than $1.11 \times 10^{5} \mathrm{~A} / \mathrm{cm}^{2}$ for the standard model. This increase may be attributed to the decrease in bump resistance since the cross section of the bump became larger after the enlargement of the UBM opening.

TABLE IV. Maximum current density and crowding ratios at different cross sections for the solder joint with various thicknesses of Cu UBM.

\begin{tabular}{|c|c|c|c|c|c|c|c|c|}
\hline & & & \multicolumn{6}{|c|}{ Cross section } \\
\hline \multicolumn{3}{|c|}{ Method } & $\begin{array}{c}\text { Y1, UBM } \\
\text { layer }\end{array}$ & $\begin{array}{l}\text { Y2, IMC } \\
\text { layer }\end{array}$ & $\begin{array}{c}\text { Y3, top } \\
\text { layer of solder }\end{array}$ & $\begin{array}{c}\text { Y4, middle } \\
\text { layer of solder }\end{array}$ & $\begin{array}{l}\text { Y5, necking } \\
\text { layer of solder }\end{array}$ & $\begin{array}{c}\text { Y6, bottom } \\
\text { layer of solder }\end{array}$ \\
\hline \multirow[t]{6}{*}{ UBM Cu thickness $(\mu \mathrm{m})$} & 0.7 & Maximum & $2.58 \times 10^{5}$ & $2.36 \times 10^{5}$ & $1.17 \times 10^{5}$ & $4.07 \times 10^{3}$ & $8.23 \times 10^{3}$ & $6.10 \times 10^{3}$ \\
\hline & & Ratio & 51.5 & 47.1 & 23.4 & 0.8 & 1.6 & 1.2 \\
\hline & 5 & Maximum & $6.15 \times 10^{5}$ & $7.53 \times 10^{4}$ & $4.37 \times 10^{4}$ & $3.31 \times 10^{3}$ & $7.75 \times 10^{3}$ & $5.92 \times 10^{3}$ \\
\hline & & Ratio & 122.6 & 15.0 & 8.7 & 0.7 & 1.5 & 1.2 \\
\hline & 20 & Maximum & $1.55 \times 10^{6}$ & $1.27 \times 10^{4}$ & $7.54 \times 10^{3}$ & $3.04 \times 10^{3}$ & $7.71 \times 10^{3}$ & $5.78 \times 10^{3}$ \\
\hline & & Ratio & 309.2 & 2.5 & 1.5 & 0.6 & 1.5 & 1.2 \\
\hline
\end{tabular}
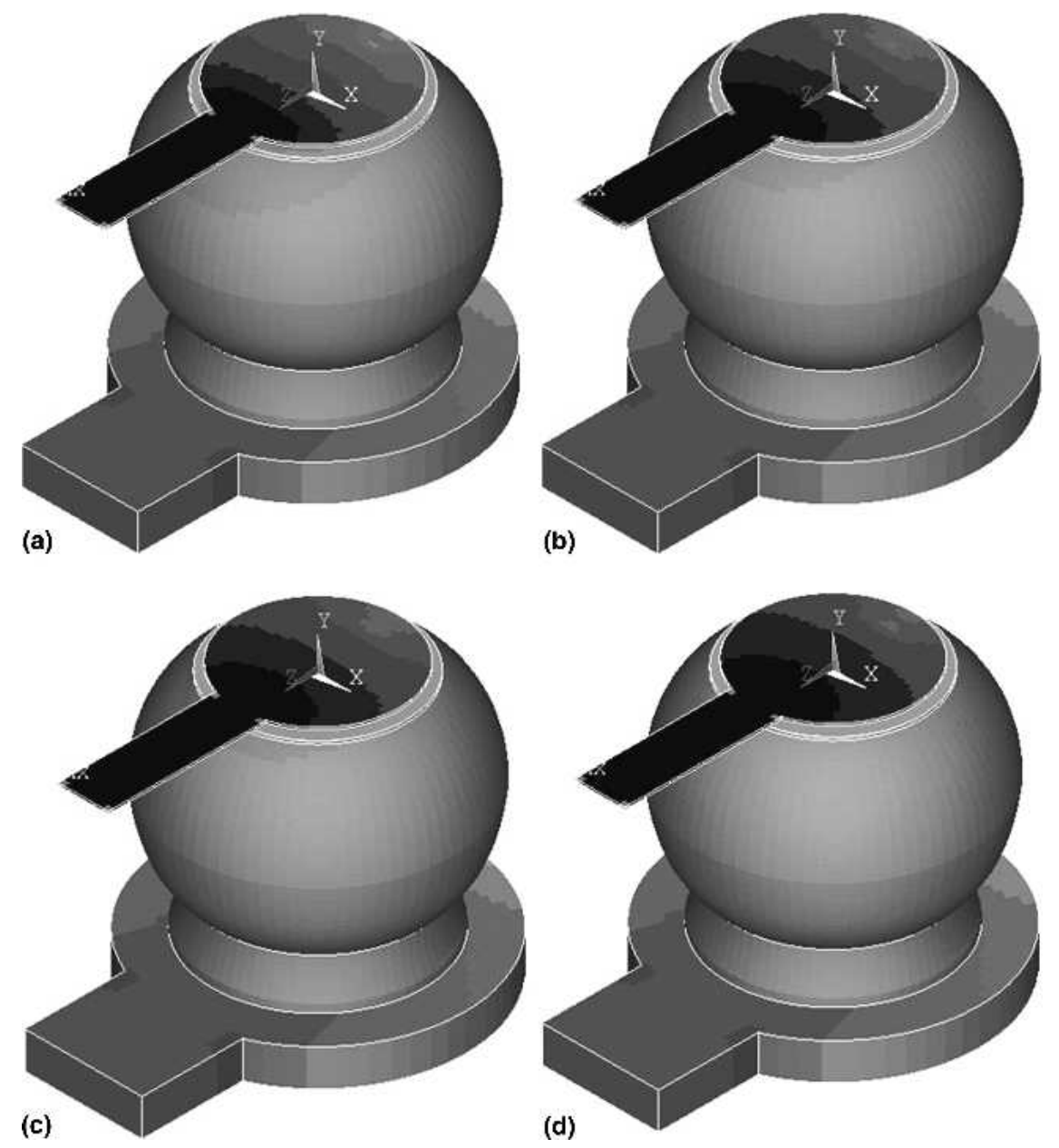

FIG. 6. 3D current density distribution in the solder joint with different UBM resistivity values: (a) $295.4 \mu \Omega \mathrm{cm}$, (b) $1477 \mu \Omega \mathrm{cm}$, (c) $2954 \mu \Omega$ $\mathrm{cm}$, and (d) $14770 \mu \Omega \mathrm{cm}$. 
Table III lists the maximum current density and the corresponding crowding ratio at cross sections Y1 to Y6 for this model. Hence, solder bumps with larger passivation opening have no effect on relieving the current crowding effect.

\section{B. Effect of UBM thickness}

To examine the effect of UBM thickness on the distribution of current density, three thicknesses of $\mathrm{Cu}$ UBM were simulated, including $0.7,5$, and $20 \mu \mathrm{m}$. Figures 5(a)-5(c) show the 3D distribution of current density in the solder joints for the three models, respectively. Although serious current crowding still occurs near the entrance of the $\mathrm{Al}$ trace for the three models, the solder bump is moved away from the crowding site due to the thicker UBM. The net effect is a lower maximum current density in the solder joint, and the current density inside the solder becomes more uniform. The maximum current density and the corresponding crowding ratio at

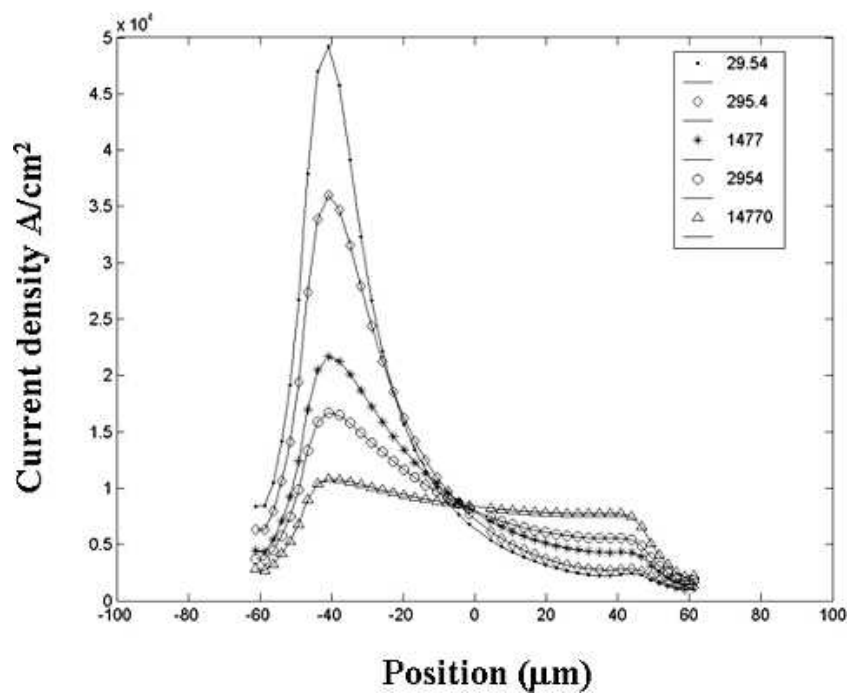

FIG. 7. Current density distribution inside the solder along the $\mathrm{Z}$ axis for the five UBM resistivity values at the top layer of the solder (cross-section Y3). cross sections $\mathrm{Y} 1$ to $\mathrm{Y} 6$ for the three models are listed in Table IV. The maximum current densities in the top layer of the solder are $1.17 \times 10^{5}, 4.37 \times 10^{4}$, and $7.54 \times$ $10^{3} \mathrm{~A} / \mathrm{cm}^{2}$, respectively. It was surprising that the value dramatically decreased to $7.54 \times 10^{3} \mathrm{~A} / \mathrm{cm}^{2}$ for the solder joint with $20-\mu \mathrm{m} \mathrm{Cu} \mathrm{UBM}$, which corresponds to a low crowding ratio of 1.5. Thus, the current crowding effect inside the solder bump was effectively relieved by adding a thick UBM, that is, by moving the UBM/solder interface away from the current crowding region.

\section{Effect of UBM resistivity}

The best method of suppressing the current crowding effect in this study was to use a resistive UBM layer. In this simulation, we simulated four solder joints with 295 , 1477,2954 , and $14770 \mu \Omega \mathrm{cm}$, which corresponded to $10,50,100$, and 500 times the UBM resistivity of the standard model. Figures 6(a)-6(d) show the 3D distribution of current density in the solder joint for the four models. It was found that the current density redistributed in the contact opening. With the increase in UBM resistivity, a greater amount of current traveled further along the Al pad before flowing down into the contact opening. In addition, the current density distribution in the top layer of the solder became more uniform as UBM resistivity increased. Figure 7 shows the current density distribution inside the top layer of the solder along the $\mathrm{Z}$ axis. The current became uniformly distributed inside the solder layer, and maximum current densities ranged from 7.01 to $1.55 \times 10^{4} \mathrm{~A} / \mathrm{cm}^{2}$. The corresponding crowding ratios are 14.0, 7.4, 5.4, and 3.1 for the solder joint with UBM resistivities of 295, 1477, 2954, and $14770 \mu \Omega \mathrm{cm}$, respectively, as listed in Table V. Furthermore, the current distribution in the UBM, IMC layers, and solder bump also became more uniform when highly resistive UBM layers were used.

Because the insertion of the resistive layers may increase the bump resistance and thus cause higher Joule heating in the solder joints, thermal simulation was performed to examine temperature distribution in the above

TABLE V. Maximum current density and crowding ratios at different cross sections for the solder joint with various UBM with high resistivities.

\begin{tabular}{|c|c|c|c|c|c|c|c|c|}
\hline & \multirow[b]{2}{*}{ Method } & & \multicolumn{6}{|c|}{ Cross section } \\
\hline & & & $\begin{array}{l}\text { Y1, UBM } \\
\text { layer }\end{array}$ & $\begin{array}{l}\text { Y2, IMC } \\
\text { layer }\end{array}$ & $\begin{array}{l}\text { Y3, top layer } \\
\text { of solder }\end{array}$ & $\begin{array}{l}\text { Y4, middle } \\
\text { layer of solder }\end{array}$ & $\begin{array}{l}\text { Y5, necking } \\
\text { layer of solder }\end{array}$ & $\begin{array}{c}\text { Y6, bottom } \\
\text { layer of solder }\end{array}$ \\
\hline \multirow{10}{*}{$\begin{array}{l}\text { UBM resistivity } \\
(\mu \Omega \cdot \mathrm{cm})\end{array}$} & \multirow[t]{2}{*}{295.4} & Maximum & $9.52 \times 10^{4}$ & $1.04 \times 10^{5}$ & $7.01 \times 10^{4}$ & $3.40 \times 10^{3}$ & $7.45 \times 10^{3}$ & $5.87 \times 10^{3}$ \\
\hline & & Ratio & 19.0 & 20.8 & 14.0 & 0.7 & 1.5 & 1.2 \\
\hline & \multirow[t]{2}{*}{1477} & Maximum & $4.34 \times 10^{4}$ & $5.00 \times 10^{4}$ & $3.69 \times 10^{4}$ & $3.23 \times 10^{3}$ & $7.27 \times 10^{3}$ & $5.80 \times 10^{3}$ \\
\hline & & Ratio & 8.7 & 10.0 & 7.4 & 0.6 & 1.5 & 1.2 \\
\hline & \multirow[t]{2}{*}{2954} & Maximum & $2.96 \times 10^{4}$ & $3.49 \times 10^{4}$ & $2.68 \times 10^{4}$ & $3.16 \times 10^{3}$ & $7.17 \times 10^{3}$ & $5.76 \times 10^{3}$ \\
\hline & & Ratio & 5.9 & 7.0 & 5.4 & 0.6 & 1.4 & 1.2 \\
\hline & \multirow[t]{2}{*}{14770} & Maximum & $1.49 \times 10^{4}$ & $1.87 \times 10^{4}$ & $1.55 \times 10^{4}$ & $3.10 \times 10^{3}$ & $7.04 \times 10^{3}$ & $5.71 \times 10^{3}$ \\
\hline & & Ratio & 3.0 & 3.7 & 3.1 & 0.6 & 1.4 & 1.1 \\
\hline & \multirow[t]{2}{*}{29540} & Maximum & $1.25 \times 10^{4}$ & $1.60 \times 10^{4}$ & $1.36 \times 10^{4}$ & $3.10 \times 10^{3}$ & $7.01 \times 10^{3}$ & $5.70 \times 10^{3}$ \\
\hline & & Ratio & 2.5 & 3.2 & 2.7 & 0.6 & 1.4 & 1.1 \\
\hline
\end{tabular}


models. Figures 8(a)-8(e) show the temperature distributions in the solder joints with 29.5 (standard model), 295, 1477, 2954, and $14770 \mu \Omega \cdot \mathrm{cm}$ UBM, respectively. The solder joints were applied by $0.567 \mathrm{~A}$, and the bottom of the BT substrate was maintained at $70{ }^{\circ} \mathrm{C}$. For the standard model in Fig. 8(a), the average temperature in the solder bump was $94.5^{\circ} \mathrm{C}$, which was obtained by averaging the temperatures in the white dotted line in the figure. The solder near the entrance area of the $\mathrm{Al}$ trace has higher temperature of $98.8^{\circ} \mathrm{C}$. As the resistivity of the UBM increased, Joule heating effect became significant, as shown in Figures 8(b)-8(e). The temperature increase due to Joule heating was as large as $30.7{ }^{\circ} \mathrm{C}$ for the solder joint with $14770 \mu \Omega \mathrm{cm}$ UBM. However, the current flowing in the solder joints is generally less than 0.2 A during device operation. Figure 8(f) shows the temperatures in the solder joints as a function of applied current up to $0.567 \mathrm{~A}$. It is found that Joule heating effect was not serious under $0.2 \mathrm{~A}$. For the standard model, the temperature increase was $2.2^{\circ} \mathrm{C}$, whereas it was $2.8^{\circ} \mathrm{C}$ for the solder joint with $14770 \mu \Omega \mathrm{cm}$ UBM. This indicates that the temperature increase due to the resistive UBM was only $0.6^{\circ} \mathrm{C}$ at $0.2 \mathrm{~A}$.

\section{DISCUSSION}

Figures 9(a)-9(c) depict the crowding ratios at cross sections $\mathrm{Y} 1$ to $\mathrm{Y} 6$ for the above four methods. It is clear

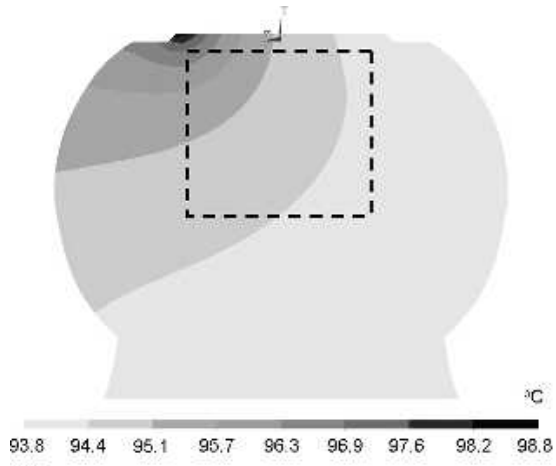

(a)

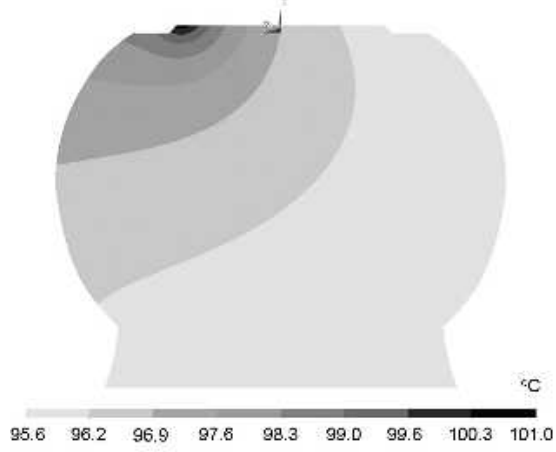

(c)

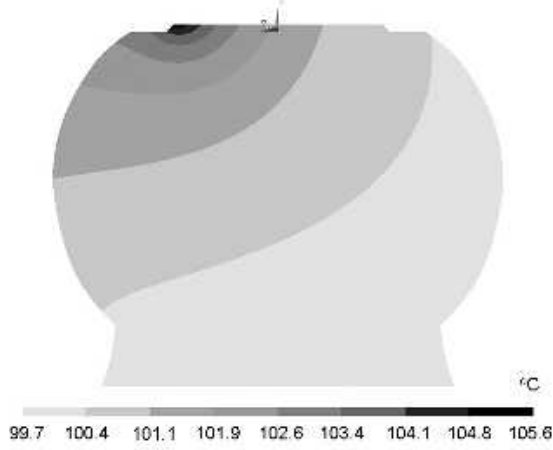

(e)

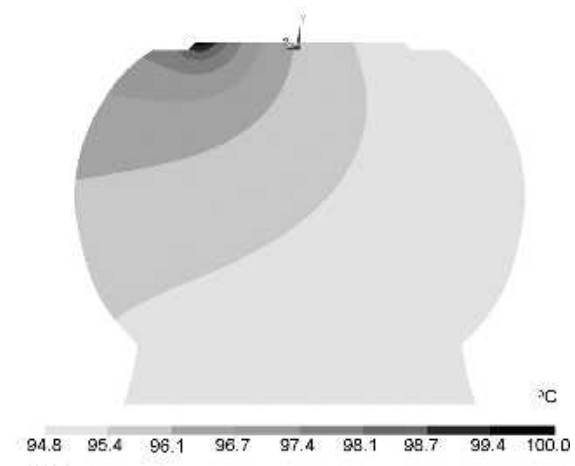

(b)

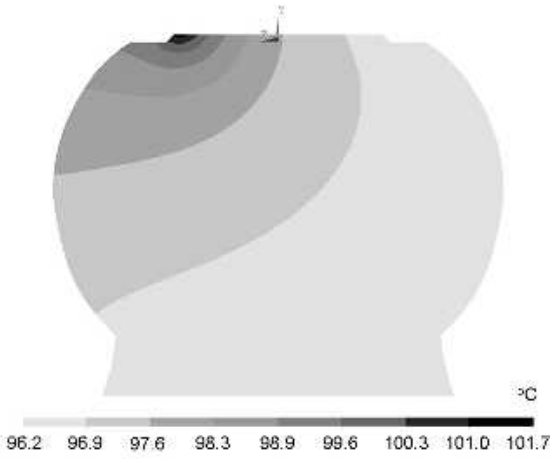

(d)

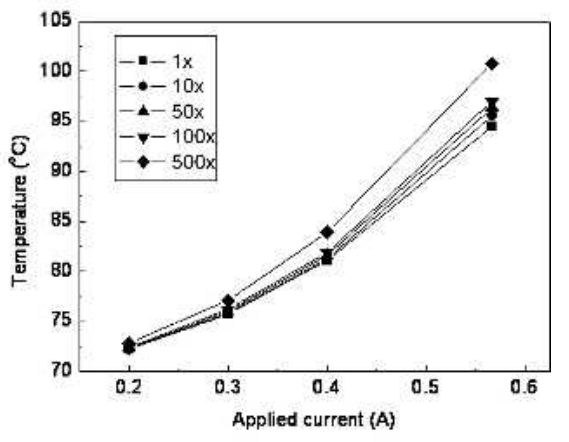

(f)

FIG. 8. Temperature distribution in the solder bumps when stressed by $0.567 \mathrm{~A}$ : (a) standard model, (b) solder joint with resistive UBM of $295.4 \mu \Omega \cdot \mathrm{cm}$, (c) solder joint with resistive UBM of $1477 \mu \Omega \cdot \mathrm{cm}$, (d) solder joint with resistive UBM of $2954 \mu \Omega \cdot \mathrm{cm}$, (e) solder joint with resistive UBM of $14770 \mu \Omega \cdot \mathrm{cm}$, and (f) simulated temperature in the solder joint as a function of applied current up to 0.567 A. 


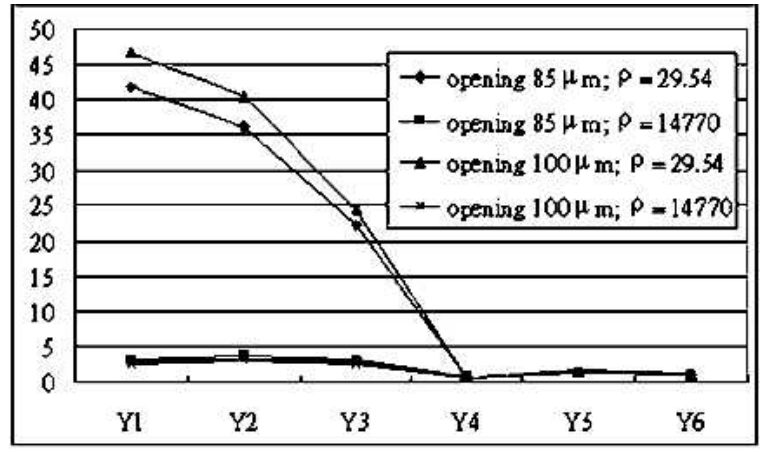

(a)

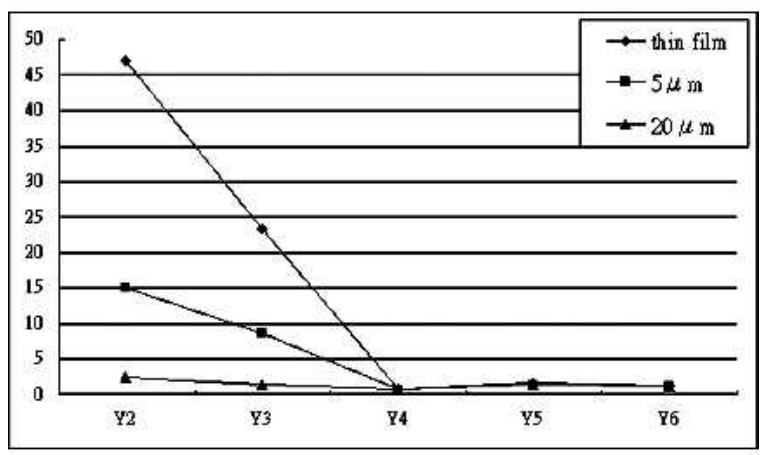

(b)

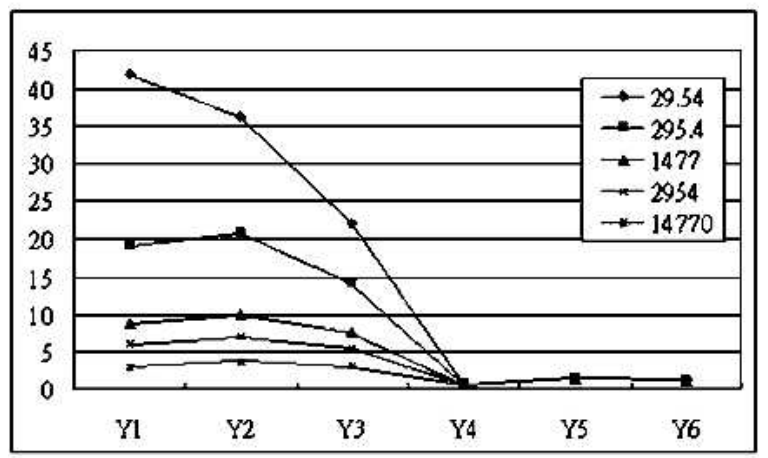

(c)

FIG. 9. The crowding ratios for the $\mathrm{Y} 1$ to $\mathrm{Y} 6$ cross-sections for (a) effect of dimension of passivation opening, (b) effect of $\mathrm{Cu}$ UBM thickness, and (c) effect of UBM resistance. It shows that the current crowding effect can be successfully relieved in the solder joints with a thick $\mathrm{Cu}$ UBM or with the highly resistive UBM.

that there is no effect on relieving current crowding by the enlargement of the passivation opening, as shown in Fig. 9(a). A thicker $\mathrm{Cu}$ UBM can relieve current crowding in the solder bump by moving the UBM/solder interface away from the current crowding region, as seen in Fig. 9(b). The thicker the UBM is, the less the current crowding effect. Figure 9(c) shows that the crowding ratios in the solder joint can be lowered to 3.1 through use of more resistant UBM. This UBM layer can suppress current crowding at the UBM/solder interface.

The best methods for relieving the current crowding effect inside the solder bump fall into two categories: (i) moving the UBM/solder interface away from the current crowding region, and (ii) suppressing current crowding at the UBM/solder interface. If the UBM/solder interface can be moved away from the current crowding region, the threat from the high current density can be avoided. As shown in Figs. 6(a)-6(c), one can clearly see that the current density drops very rapidly when it is moved way from the chip side. Therefore, if one increases the thickness of UBM, the current crowding region will locate within the UBM, and therefore, the $\mathrm{UBM} /$ solder interface will be further away from it. Thick $\mathrm{Cu}$ UBM has been adopted for use in the flip-chip solder joints. ${ }^{14}$ Thus, it is expected the joints would have better electromigration resistance.

To suppress the current crowding effect, the best scenario would be to have the current flowing though the whole solder uniformly. To achieve this goal, increasing the resistivity of UBM would be the best method. Our simulation shows that the current crowding ratio can be reduced to 3.1 when the UBM resistivity is increased to $4770 \mu \Omega \mathrm{cm}$. However, the tradeoff is the increase in the resistance of the solder joint. The vertical resistance of the standard model was estimated to be $1.2 \mathrm{~m} \Omega$. The total resistances of the solder joint became 1.4, 2.1, 3.0, and $10.3 \mathrm{~m} \Omega$ for the solder joints with a UBM resistivity of 295, 1477, 2954, and $14770 \mu \Omega \mathrm{cm}$, respectively. This resistive layer could be a TiN, TaN, or Ta material, and could be deposited with UBM, or it could be an additional layer between the Al pad and the UBM. Furthermore, our thermal simulation shows that the Joule heating effect due to the resistive layers was less than $0.6{ }^{\circ} \mathrm{C}$ when the applied current was less than $0.2 \mathrm{~A}$. Therefore, the insertion of the resistive layers could relieve current crowding effect significantly and cause very small Joule heating effect at low applied current. Nevertheless, it is still unknown if it is compatible with the current flip-chip manufacturing process, and thus it requires further experimental study.

Furthermore, one can use the hybrid of the above approaches to relieve the current crowding effect. If one adopts the highly resistant layer to relieve the current crowding effect, increasing the cross-section of the passivation opening would have a further effect in reducing the maximum current density in the solder bump. When the model in Sec. III. B is used with a larger passivation opening and the high resistivity UBM of $14770 \mu \Omega \mathrm{cm}$ is adopted, the maximum current density can be further reduced down from $1.6 \times 10^{4}$ to $1.3 \times 10^{4} \mathrm{~A} / \mathrm{cm}^{2}$.

\section{CONCLUSIONS}

A three-dimensional simulation was used to demonstrate that current crowding in the solder joints can be successfully suppressed either by thick Cu UBM or a highly resistive UBM layer. The crowding ratio in the 
solder can be reduced from 23.4 to 1.5 when a $20-\mu \mathrm{m} \mathrm{Cu}$ UBM is used, and it can be diminished to 3.1 when a $0.7-\mu \mathrm{m}$ UBM of $14770 \mu \Omega \mathrm{cm}$ in resistivity is adopted. In addition, the current crowding effect could not be relieved merely by increasing the diameter of the passivation opening or changing the angle between the $\mathrm{Al}$ trace and the $\mathrm{Cu}$ line. The solder joints with a lower crowding ratio were expected to have better electromigration resistance, and experimental data are needed to verify the simulation results.

\section{ACKNOWLEDGMENTS}

The authors would like to thank the National Science Council of the Republic of China for financial support through Grant No. 92-2216-E-009-008. In addition, the assistance of the simulation facility from the National Center for High-performance Computing (NCHC) in Taiwan is appreciated.

\section{REFERENCES}

1. R. Glenn: Blackwell, The Electronic Packaging Handbook, CRC Press in cooperation with IEEE Press, Boca Raton, FL (2000).

2. The International Technology Roadmap for Semiconductor (Semiconductor Industry Association, San Jose, CA, 2003).

3. K.N. Tu: Recent advances on electromigration in very-large-scaleintegration of interconnects, J. Appl. Phys. 94, 5451 (2003).

4. S. Brandenburg and S. Yeh: Electromigration studies of flip chip bump solder joints, in Proceedings of Surface Mount International
Conference and Exhibition, San Jose, CA (SMTA, Edina MN 1998), p. 337.

5. C.Y. Liu, C. Chen, C.N. Liao, and K.N. Tu: Microstructureelectromigration correlation in a thin strips of eutectic $\mathrm{SnPb}$ solder stressed between Cu electrodes. Appl. Phys. Lett. 75, 58 (1999).

6. P.S. Ho and T. Kwok: Electromigration in metals, Rep. Prog. Phys. 52, 301 (1989).

7. C.K. Hu and J.M.E. Harper: Copper interconnections and reliability. Mater. Chem. Phys. 52, 5 (1998).

8. E.C.C. Yeh, W.J. Choi, and K.N. Tu: Current-crowding-induced electromigration failure in flip chip solder joints. Appl. Phys. Lett. 80(4), 580 (2002).

9. W.J. Choi, ECC. Yeh, and K.N. Tu: Mean-time-to-failure study of flip chip solder joints on $\mathrm{Cu} / \mathrm{Ni}(\mathrm{V}) / \mathrm{Al}$ thin-film under-bumpmetallization. J. Appl. Phys. 94, 5665 (2003).

10. J.W. Nah, K.W. Paik, and J.O. Suh: Mechanism of electromigration-induced failure in the $97 \mathrm{~Pb}-3 \mathrm{Sn}$ and $37 \mathrm{~Pb}-63 \mathrm{Sn}$ composite solder joints. J. Appl. Phys. 94, 7560 (2003).

11. J.D. Wu, C.W. Lee, P.J. Zheng, J.C.B. Lee, and S. Li: Electromigration reliability of $\mathrm{SnAg}_{\mathrm{x}} \mathrm{Cu}_{\mathrm{y}}$ flip chip interconnects, in 2004 Electronic Components and Technology Conference, (IEEE, New York) p. 961.

12. T.L. Shao, S.H. Chiu, C. Chen, D.J. Yao, and C.Y. Hsu: J. Electron. Mater. 33, 1350 (2004).

13. T.Y. Tom Lee, T.Y. Lee, and K.N. Tu: A study of electromigration in 3D flip chip solder joint using numerical simulation of heat flux and current density, in Proceedings of the 51th Electronic Components and Technology Conference, Packaging, and Manufacturing Technology Society, (2001), p. 558.

14. J.W. Jang, L.N. Ramanathan, J.K. Lin, and D.R. Frear: Spalling of $\mathrm{Cu}_{3} \mathrm{Sn}$ intermetallics in high-lead 95Pb5Sn solder bumps on $\mathrm{Cu}$ under bump metallization during solid-state annealing. J. Appl. Phys. 95, 8286 (2004). 